\title{
ENHANCEMENT OF HYDROSTATIC RESISTANCE AND MECHANICAL PERFORMANCE OF WATERPROOF BREATHABLE LAMINATED FABRICS
}

\author{
Abdur Razzaque*, Pavla Tesinova, Lubos Hes \\ Department of Textile Evaluation, Technical University of Liberec, Studentska 1402/2, Liberec, Czech Republic; \\ corresponding author e-mail: araztm29@yahoo.com
}

\begin{abstract}
:
Waterproof breathable laminated fabrics have the special property that permits water vapour to pass through but protects by preventing the entrance of liquid water. Different characteristic properties of the layered constructions of these fabrics have good influence on their hydrostatic resistance and mechanical performance. This research study presents an experiment to enhance the hydrostatic resistance and tensile strength of four different types of hydrophobic membrane laminated waterproof fabrics by considering their breathability as well. For this purpose, water repellent coating based on $\mathrm{C}_{6}$-fluorocarbon resin along with polysiloxane hydrophobic softening agent was applied on these four different types of laminated fabrics using pad-dry-cure method. The coated fabrics were characterised by performing different experiments to evaluate the effect of coating on their hydrostatic resistance and mechanical property as well as on water vapour permeability and air permeability. From the test results and analysis of variance (ANOVA), it was found that hydrostatic resistance and tensile strength of the laminated fabrics were enhanced after coating along with proper water repellent property, whereas there were no significant changes in their water vapour permeability and air permeability.
\end{abstract}

\section{Keywords:}

Waterproof, water repellent, hydrostatic resistance, tensile strength, breathability

\section{Introduction}

The term waterproof can be described as the impermeability to water. Waterproof fabric has fewer open pores; as a result, this fabric is less permeable to the passage of air and water vapour, but it is resistant to the penetration of water even under higher hydrostatic pressure [14]. On the other hand, the term fabric breathability can be described as the ability of clothing to permit the transmission of water vapour from inside to outside atmosphere by diffusion and, hence, facilitate evaporative cooling. It is determined by water vapour permeability [6]. In severe environmental conditions, waterproof breathable fabrics protect the human body from external water, but they allow moisture vapour to be transmitted from inside to outside. So, these fabrics balance two contradictory properties. As a result, they are significant in the fields of protective clothing, sportswear and construction industries [10]. However, different types of waterproof breathable fabrics can be classified as like as closely woven fabrics, micro-porous membranes and coating, hydrophilic membranes and coating, combination of micro-porous and hydrophilic membranes and coating, retroreflective microbeads, smart breathable fabrics and fabrics based on biomimetics [8, 12, 15, 17]. Again, waterrepellent fabrics are those that resist being wetted by water. Here, water drops roll off the fabrics [5]. These types of fabrics can be made by depositing hydrophobic materials on the fibre's surface. They have open pores and are permeable to air and water vapour. They still increase the water resistance property but permit the passage of liquid water under higher hydrostatic pressure [14].
Comfort is a basic requirement in the selection of clothing for all conditions [1]. Tactile comfort, thermal comfort and aesthetic comfort are three main categories of clothing comfort [18]. It can also be categorised as a mechanical comfort that can be evaluated by fabric handle, rigidity, tensile strength and smoothness. Thermal comfort can be assessed by air permeability along with permeability of water vapour and heat. However, core temperature of the human body is approximately $37^{\circ} \mathrm{C}$. When core body temperature exceeds $37^{\circ} \mathrm{C}$ under different conditions, perspiration is produced in order to balance the core temperature by secretion of sweat. It is important for clothing to play a role for keeping the body comfortable by removing sweat as water vapour [11].

This study worked on four different types of microporous polytetrafluoroethylene (PTFE) membrane laminated layered waterproof fabrics that are used as sports clothing. Laminated PTFE microporous fabrics have holes that are much smaller $(2-3 \mu \mathrm{m})$ than the size of the smallest raindrops $(100 \mu \mathrm{m})$, yet are much larger than the size of water vapour molecule (40 $\left.\times 10^{-6} \mu \mathrm{m}\right)$ [2]. That is why water droplets cannot penetrate the fabric but water vapour molecules can penetrate. In the experiment, water-repellent coating solution was prepared by ecologically optimised $\mathrm{C}_{6}$-based fluorocarbon resin instead of conventional $\mathrm{C}_{8}$-based fluorocarbon resin along with polysiloxane hydrophobic softening agent. Then this coating solution was applied on those four different PTFE laminated fabrics by pad-dry-cure method. The purpose of coating on the laminated fabrics was the enhancement of the existing hydrostatic resistance and tensile strength of the fabrics whilst 
keeping breathability and air permeability in mind. It was found from the test results and statistical analysis that hydrostatic resistance and tensile strength were significantly increased after coating, whereas there were no significant changes in the results of water vapour permeability and air permeability. Moreover, all the fabrics showed proper water-repellent property, which is important for outdoor sports clothing.

\section{Experimental}

\subsection{Materials}

\section{Waterproof laminated fabrics}

Four different types of PTFE hydrophobic micro-porous membrane laminated waterproof fabrics were used in the experiment. All the samples were three layered fabrics. Outer layers of all four samples were of polyethylene terephthalate (PET) plain woven structures. Inner layers of first two samples were with PET knitted structures and inner layers of third and fourth samples were with PET fleece knitted structures. PTFE membrane was laminated as a middle layer for each sample. Particulars of laminated sample fabrics are given in Table 1.

\section{Coating chemicals}

${ }^{\circledR}$ RUCOSTAR EEE6 was used as a water-repellent chemical, which is a $\mathrm{C}_{6}$-based fluorocarbon resin with a density of $1.03 \mathrm{~g} /$ $\mathrm{cm}^{3}$ at $20^{\circ} \mathrm{C}$. This chemical is different from conventional $\mathrm{C}_{8}$-based fluorocarbon resin. It is ecologically optimised agent for water and free from perfluorooctanoic acid (PFOA), perfluorooctane sulphonic acid (PFOS) and alkylphenol ethoxylate (APEO). Cationic polysiloxane ${ }^{\circledR}$ RUCOFIN HSF was used as a hydrophobic softening agent in the coating solution. This chemical is easily diluted with water and its density is $1.10 \mathrm{~g} / \mathrm{cm}^{3}$ at $20^{\circ} \mathrm{C}$. Both the chemicals were purchased from Rudolf $\mathrm{GmbH}$, Germany.

\subsection{Methods}

\section{Coating process}

Pad-dry-cure method was used for coating process. About $50 \mathrm{~g} / \mathrm{L}$ of $\mathrm{C}_{6}$-based fluorocarbon resin ( ${ }^{\circledR} \mathrm{RUCOSTAR}$ EEE6) was added as a water-repellent chemical with $15 \mathrm{~g} / \mathrm{L}$ of polysiloxane hydrophobic softening agent ( ${ }^{\circledR}$ RUCOFIN HSF) in order to prepare the coating solution in the experiment, and this recipe was determined after making trials with different ratios of these two chemicals according to manufacturer's recommendation. The homogeneous coating solution was made by ordinary manual stirring and put into the coating bath. The waterproof fabrics were impregnated in the coating bath at room temperature. The coating fluid was agitated by glass rod to have uniform coating on the fabrics. After impregnation, the fabrics were passed through the squeezing rollers. Then the fabrics were dried and finally cured at $160^{\circ} \mathrm{C}$ for $1 \mathrm{~min}$.

\section{Evaluation of fabric characteristics}

Cover factor of outer woven layer part of the laminated fabric was measured using the following pierce equation:

$$
\left(\mathrm{K}_{1}+\mathrm{K}_{2}\right)=\mathrm{n}_{1} /\left(\mathrm{N}_{1}\right)^{1 / 2}+\mathrm{n}_{2} /\left(\mathrm{N}_{2}\right)^{1 / 2}
$$

Here, $\mathrm{K}_{1}$ is the warp cover factor, $\mathrm{K}_{2}$ is the weft cover factor, $\mathrm{n}_{1}$ is the warp yarn density per inch, $\mathrm{n}_{2}$ is the weft yarn density per inch, $N_{1}$ is the English warp yarn count and $N_{2}$ is the English weft yarn count.

Stitch density of inner knitted layer part of the laminated fabric was calculated by the multiplication of courses per centimetre and wales per centimetre using optical microscope.

Fabric weight per unit area before and after coating was measured using electronic weighing scale according to EN 12127 standard.

Fabric thickness before and after coating was measured according to EN ISO 5084 standard at a pressure of $100 \mathrm{~Pa}$ using Louis Schopper Automatic Micrometer.

Fabric density of the whole sample before and after coating was calculated using the following equation:

$$
\text { Fabric density }=\mathrm{W} / \mathrm{t}\left[\mathrm{kg} / \mathrm{m}^{3}\right]
$$

Here, $W$ is the fabric weight per unit area and $t$ is the fabric thickness.

Fabric characteristics before and after coating as well as increase in areal density after coating are given in Table 2.

\section{Morphology}

The morphological cross sections of four different types of laminated samples show the layered structures of the fabrics

Table 1. Particulars of laminated sample fabrics

\begin{tabular}{|c|c|c|c|}
\hline $\begin{array}{c}\text { Fabric sample } \\
\text { code }\end{array}$ & Fabric construction (outer layer to \\
inner layer) & $\begin{array}{c}\text { Cover factor of outer woven } \\
\text { part of fabric }\left(\mathbf{K}_{\mathbf{1}}+\mathbf{K}_{\mathbf{2}}\right)\end{array}$ & $\begin{array}{c}\text { Stitch density of inner } \\
\text { knitted part of fabric } \\
\text { (stitches/cm } \mathbf{~})\end{array}$ \\
\hline WMK-1 & PET plain + PTFE + PET knitting & 17 & 273 \\
\hline WMK-2 & PET plain + PTFE + PET knitting & 33 & 925 \\
\hline WMF-3 & PET plain + PTFE + PET knitted fleece & 27 & 192 \\
\hline WMF-4 & PET plain + PTFE + PET knitted fleece & 28 & 221 \\
\hline
\end{tabular}


Table 2. Characteristics of fabrics before and after coating

\begin{tabular}{|c|c|c|c|c|c|c|c|}
\hline $\begin{array}{c}\text { Fabric } \\
\text { sample } \\
\text { code }\end{array}$ & $\begin{array}{c}\text { Areal } \\
\text { density of } \\
\text { uncoated } \\
\text { fabric }\left(g / \mathbf{m}^{2}\right)\end{array}$ & $\begin{array}{c}\text { Areal } \\
\text { density } \\
\text { of coated } \\
\text { fabric }\left(\mathbf{g} / \mathrm{m}^{2}\right)\end{array}$ & $\begin{array}{c}\text { Increase in } \\
\text { areal density } \\
\text { after coating } \\
\text { (\%) }\end{array}$ & $\begin{array}{l}\text { Thickness } \\
\text { of uncoated } \\
\text { fabric }(\mathrm{mm})\end{array}$ & $\begin{array}{l}\text { Thickness } \\
\text { of coated } \\
\text { fabric }(\mathrm{mm})\end{array}$ & $\begin{array}{c}\text { Density of } \\
\text { uncoated } \\
\text { fabric } \\
\left(\mathbf{k g} / \mathrm{m}^{3}\right)\end{array}$ & $\begin{array}{c}\text { Density } \\
\text { of coated } \\
\text { fabric } \\
\left(\mathrm{kg} / \mathrm{m}^{3}\right)\end{array}$ \\
\hline & Mean \pm SD & Mean \pm SD & & Mean \pm SD & Mean \pm SD & Mean \pm SD & Mean \pm SD \\
\hline WMK-1 & $89 \pm 2.24$ & $99 \pm 2.31$ & 11.24 & $0.21 \pm 0.01$ & $0.23 \pm 0.01$ & $423.81 \pm 2.21$ & $430.43 \pm 4.85$ \\
\hline WMK-2 & $167 \pm 2.29$ & $185 \pm 2.19$ & 10.78 & $0.35 \pm 0.01$ & $0.38 \pm 0.01$ & $477.14 \pm 2.20$ & $486.84 \pm 3.15$ \\
\hline WMF-3 & $314 \pm 1.62$ & $339 \pm 3.74$ & 7.96 & $1.20 \pm 0.01$ & $1.25 \pm 0.02$ & $261.67 \pm 1.45$ & $271.20 \pm 2.01$ \\
\hline WMF-4 & $389 \pm 1.22$ & $418 \pm 3.56$ & 7.46 & $1.27 \pm 0.01$ & $1.32 \pm 0.02$ & $306.30 \pm 2.25$ & $316.67 \pm 1.74$ \\
\hline
\end{tabular}

before and after coating. This morphology was examined using high-resolution scanning electron microscope VEGA TS 5130TESCAN at $30 \mathrm{KV}$ accelerated voltage, which was used in the previous study [9].

\section{Spray test}

Spray test is a method to determine the resistance of a fabric to wetting by water. It is commonly used to determine the waterrepellent effect of finishes applied to fabrics. In the experiment, spray test was conducted using Pro-ser Spray Rating Tester according to AATCC 22. Before testing, the coated samples were conditioned at $21 \pm 1^{\circ} \mathrm{C}$ for $24 \mathrm{~h}$ under a relative humidity of $65 \% \pm 2 \%$. The samples were stretched on a hoop that was held at an angle of $45^{\circ}$ and $250 \mathrm{~mL}$ of water was poured through a spray nozzle. Any wetting or spotted pattern was observed and compared with the photographic rating chart [13].

\section{Hydrostatic resistance test}

Hydrostatic resistance tests were carried out using SDL ATLAS Hydrostatic Head Tester Model MO18 according to AATCC 127 or CSN EN 20811 at $20 \pm 2^{\circ} \mathrm{C}$. The rate of increase in water pressure was $60 \pm 3 \mathrm{cmH}_{2} \mathrm{O} / \mathrm{min}$. Compressor was kept at a maximum of $80 \mathrm{PSI}$. Water pressure was recorded at the point when water penetrated from outer layer to inner layer. The unit was expressed as $\mathrm{CmH}_{2} \mathrm{O}$, and the test results of uncoated and coated samples are given in Table 3.

\section{Tensile strength test}

Testometric M350-5CT machine (from the United Kingdom) was used at room temperature according to CSN EN ISO 13934-1 standard for tensile strength tests of the samples. Specimen size was kept at $20 \mathrm{~cm} \times 5 \mathrm{~cm}$, and testing speed was $100 \mathrm{~mm} /$ min. The breaking force was expressed as in Newton (N). Five sets of experiments were performed, and the average results with standard deviations are reported in Table 3.

\section{Bending rigidity test}

Bending property is a critical determining factor of fabric handle [4]. The bending force of the sample fabric was directly obtained by $\mathrm{TH}-7$ instrument as used in the previous research work [7].
Bending rigidity was calculated by the multiplication of this bending force value with a constant value $\left(0.7 \times 10^{-6}\right)$. Here, unit was expressed as $\mathrm{Nm}$. The test results are given in Table 3 .

\section{Water vapour permeability test}

In order to measure the water vapour permeability, PERMETEST instrument was used. The tests were carried out for both uncoated and coated samples without any destruction according to ISO 11092 standard. The sample was placed on a measuring head over a semipermeable foil and exposed to parallel air flow at a velocity of $1 \mathrm{~m} / \mathrm{s}$ [3]. The temperature of the measuring head was maintained at room temperature for isothermal conditions. A computer monitor connected to this instrument expressed relative water vapour permeability (RWVP) in \% and evaporative resistance $\left(R_{\text {et }}\right)$ in $\mathrm{m}^{2} \mathrm{~Pa} / \mathrm{W}$. Five tests for each sample were performed, and the average test results are given in Table 3 .

\section{Air permeability test}

Air permeability is defined as the rate of air flow passing perpendicularly under a prescribed air pressure through a known area between the two surfaces of a material. Textest FX-3300 air permeability tester, which measures airflow rate under constant air pressure [19], was used to measure air permeability of the samples according to standard EN ISO 9237. Test area of the sample was $20 \mathrm{~cm}^{2}$, and air pressure difference between the two surfaces was kept at $200 \mathrm{~Pa}$ because of the layered structures of the fabric samples. Average value of 10 measurements was taken for each sample in the unit of $\mathrm{mm} / \mathrm{s}$.

\section{Analysis of variance (ANOVA)}

In order to determine the statistical significance of variations, single factor analysis of variance (ANOVA) was determined using Microsoft Excel software. To deduce whether the variations of different properties before and after coating for a sample were either significant or not, P-value, F-ratio and $F$-critical value were examined. If $P$-value was less than 0.05 $(p<0.05)$ and F-ratio was greater than F-critical value (F-ratio $>$ F-critical value), then it was considered as a statistically significant change in the result, otherwise the change was not significant. 


\section{Results and discussion}

\section{Analysis of applied coating}

Coating solution was applied on four different types of membrane laminated fabrics. From Tables 1 and 2, it can be said that WMK-1 and WMK-2 are more dense fabrics than the others. WMK-2 is more dense than WMK-1 because of its more dense outer woven layer and inner knitted layer. WMF-3 and WMF-4 are less dense because of their higher thickness and inner fleece knitted structures. After coating, higher increases in areal density $\left(\mathrm{g} / \mathrm{m}^{2}\right)$ are obtained in case of WMK-1 and WMK2 , which are $11.23 \%$ and $10.78 \%$ increases, respectively. On the other hand, $7.96 \%$ and $7.46 \%$ increases are found for the samples of WMF-3 and WMF-4. The reason for less increase in this case may be because of their inner fleece knitted structures that cannot hold the coating solution as properly as the first two samples. However, fabric thickness properties of all four fabrics also increase after coating and these influence on their total fabric densities as well.

\section{Morphology}

The cross-sectional images of four different laminated fabrics before and after coating observed using scanning electron microscope (SEM) give a proper idea about their morphology. From the images given in Figure 1, it is evident that WMK-1, WMK-2, WMF-3 and WMF-4 have three layers and their membranes are between outer and inner layers. For all samples, upper parts of the images are outer woven layers. In case of WMK-1 and WMK-2 samples, inner parts of the images are knitted structures, but inner parts of WMF-3 and WMF-4 are knitted fleece structures. However, the coated samples show more regular and smooth surfaces under SEM. This is due to the evenly deposition of coating materials on the fabric layers; as a result, individual yarns within the fabrics are more strongly attached to each other which can increase their tensile strength as well as contribute to the higher resistance against water pressure.

\section{Water repellency}

Water-repellent property is one of the important properties for outdoor fabrics. It determines the resistance of being wetted by water. More water repellency of a fabric shows more resistant property against the wetting by water. In the spray test results, there are six ratings shown in a photographic chart according to AATCC 22 method. A specimen with complete wetting of the entire face is assigned " 0 " rating, whereas a specimen with no sticking or wetting of the face is assigned "100" rating. The rest four ratings are in between " 0 " and " 100 " ratings. In the experiment, all four coated samples showed "100" rating because of complete non-wetting properties of the fabrics because of using $\mathrm{C}_{6}$-based water-repellent fluorocarbon coating.

\section{Analysis of hydrostatic resistance}

Breathability is meaningless without proper hydrostatic resistance. It is evident from Figure 2 that there is a good positive relation between fabric density and hydrostatic resistance. Hydrostatic resistance increases with the increase in fabric density in case of both uncoated and coated fabrics. In both cases, highest hydrostatic resistance is obtained for WMK-2 sample. This is due to its higher fabric density and more compact structure than any other. For example, cover factor of its outer woven part and stitch density of its inner knitted part are denser than any other PTFE laminated fabric sample. The values of hydrostatic resistance for WMF-3 and WMF4 are less than others. Here, the reason of less hydrostatic resistance values is for their lower fabric densities than others as well as their inner knitted fleece parts cannot make higher

Table 3. Properties of sample fabrics before and after coating

\begin{tabular}{|c|c|c|c|c|c|c|c|c|c|}
\hline \multirow{2}{*}{\multicolumn{2}{|c|}{ Properties }} & \multicolumn{4}{|c|}{ Uncoated } & \multicolumn{4}{|c|}{ Coated } \\
\hline & & WMK-1 & WMK-2 & WMF-3 & WMF-4 & WMK-1 & WMK-2 & WMF-3 & WMF-4 \\
\hline \multirow{2}{*}{$\begin{array}{l}\text { Hydrostatic resistance } \\
\left(\mathrm{cmH}_{2} \mathrm{O}\right)\end{array}$} & Mean & 1464 & 1522 & 1087 & 1114 & 1616 & 1712 & 1192 & 1216 \\
\hline & SD & 6.55 & 6.13 & 4.55 & 4.11 & 7.79 & 7.36 & 6.48 & 6.24 \\
\hline \multirow{2}{*}{$\begin{array}{l}\text { Breaking force } \\
\text { (N) }\end{array}$} & Mean & 410 & 478 & 356 & 379 & 477 & 572 & 412 & 435 \\
\hline & SD & 5.50 & 7.69 & 7.94 & 9.44 & 8.47 & 8.36 & 9.58 & 10.38 \\
\hline \multirow{2}{*}{$\begin{array}{l}\text { Bending rigidity } \\
\left(10^{-6} \mathrm{Nm}\right)\end{array}$} & Mean & 7.56 & 13.58 & 27.19 & 28.10 & 8.01 & 14.63 & 28.62 & 29.53 \\
\hline & SD & 0.17 & 0.12 & 0.15 & 0.12 & 0.18 & 0.13 & 0.16 & 0.12 \\
\hline \multirow{2}{*}{$\begin{array}{l}\text { Evaporative resistance, } \\
\mathrm{R}_{\mathrm{et}}\left(\mathrm{m}^{2} \mathrm{~Pa} / \mathrm{W}\right)\end{array}$} & Mean & 6.44 & 8.42 & 11.64 & 12.76 & 6.74 & 8.84 & 11.92 & 13.00 \\
\hline & SD & 0.21 & 0.27 & 0.22 & 0.21 & 0.29 & 0.31 & 0.25 & 0.28 \\
\hline \multirow{2}{*}{$\begin{array}{l}\text { RWVP } \\
(\%)\end{array}$} & Mean & 47.60 & 42.74 & 33.58 & 30.64 & 47.28 & 42.40 & 33.26 & 30.30 \\
\hline & SD & 0.37 & 0.23 & 0.28 & 0.29 & 0.41 & 0.36 & 0.33 & 0.30 \\
\hline \multirow{2}{*}{$\begin{array}{l}\text { Air permeability } \\
(\mathrm{mm} / \mathrm{s})\end{array}$} & Mean & 1.07 & 0.72 & 1.51 & 1.32 & 1.04 & 0.68 & 1.45 & 1.26 \\
\hline & SD & 0.04 & 0.05 & 0.06 & 0.07 & 0.04 & 0.05 & 0.07 & 0.07 \\
\hline
\end{tabular}




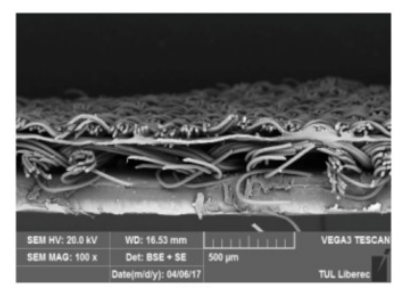

(a)

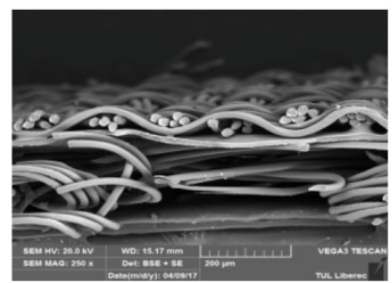

(e)

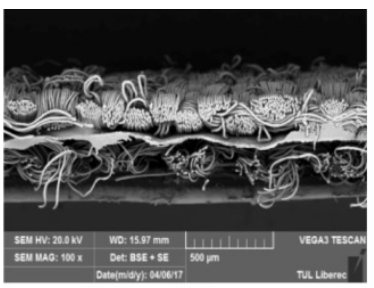

(b)

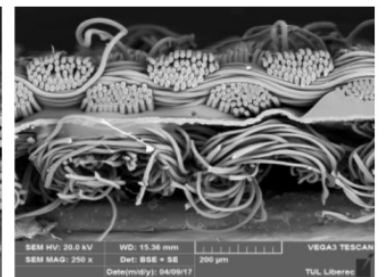

(f)

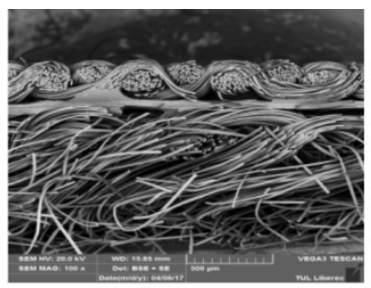

(c)

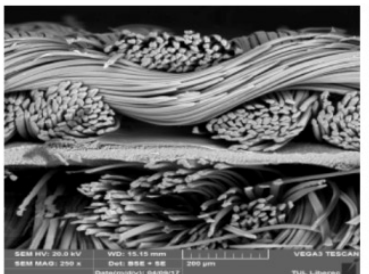

(g)

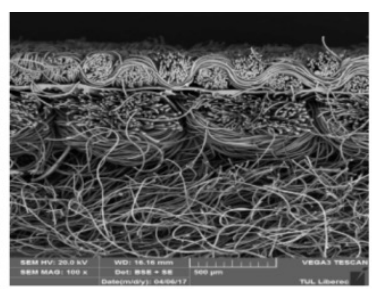

(d)

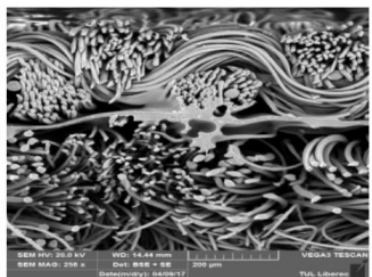

(h)

Figure 1. SEM images of uncoated samples: (a) WMK-1, (b) WMK-2, (c) WMF-3, (d) WMF-4 and coated samples: (e) WMK-1, (f) WMK-2, (g) WMF-3, (h) WMF-4.

Table 4. ANOVA for hydrostatic resistance of uncoated and coated sample fabrics

\begin{tabular}{|c|c|c|c|c|c|c|c|}
\hline $\begin{array}{c}\text { Compared pairs } \\
\text { (uncoated and coated) }\end{array}$ & $\begin{array}{l}\text { Source of } \\
\text { variation }\end{array}$ & SS & df & MS & F-ratio & P-value & F -critical \\
\hline \multirow{3}{*}{ WMK-1 } & Between groups & $34,504.17$ & 1 & 34504.17 & 444.25966 & 2.995E-05 & 7.7086474 \\
\hline & Within groups & 310.6667 & 4 & 77.66667 & & & \\
\hline & Total & $34,814.83$ & 5 & & & & \\
\hline \multirow{3}{*}{ WMK-2 } & Between groups & 54,150 & 1 & 54150 & 786.68281 & $9.613 \mathrm{E}-06$ & 7.7086474 \\
\hline & Within groups & 275.3333 & 4 & 68.83333 & & & \\
\hline & Total & $54,425.33$ & 5 & & & & \\
\hline \multirow{3}{*}{ WMF-3 } & Between groups & $16,537.5$ & 1 & 16537.5 & 351.8617 & 4.756E-05 & 7.7086474 \\
\hline & Within groups & 188 & 4 & 47 & & & \\
\hline & Total & $16,725.5$ & 5 & & & & \\
\hline \multirow{3}{*}{ WMF-4 } & Between groups & 15,606 & 1 & 15606 & 373.05179 & $4.235 \mathrm{E}-05$ & 7.7086474 \\
\hline & Within groups & 167.3333 & 4 & 41.83333 & & & \\
\hline & Total & $15,773.33$ & 5 & & & & \\
\hline
\end{tabular}

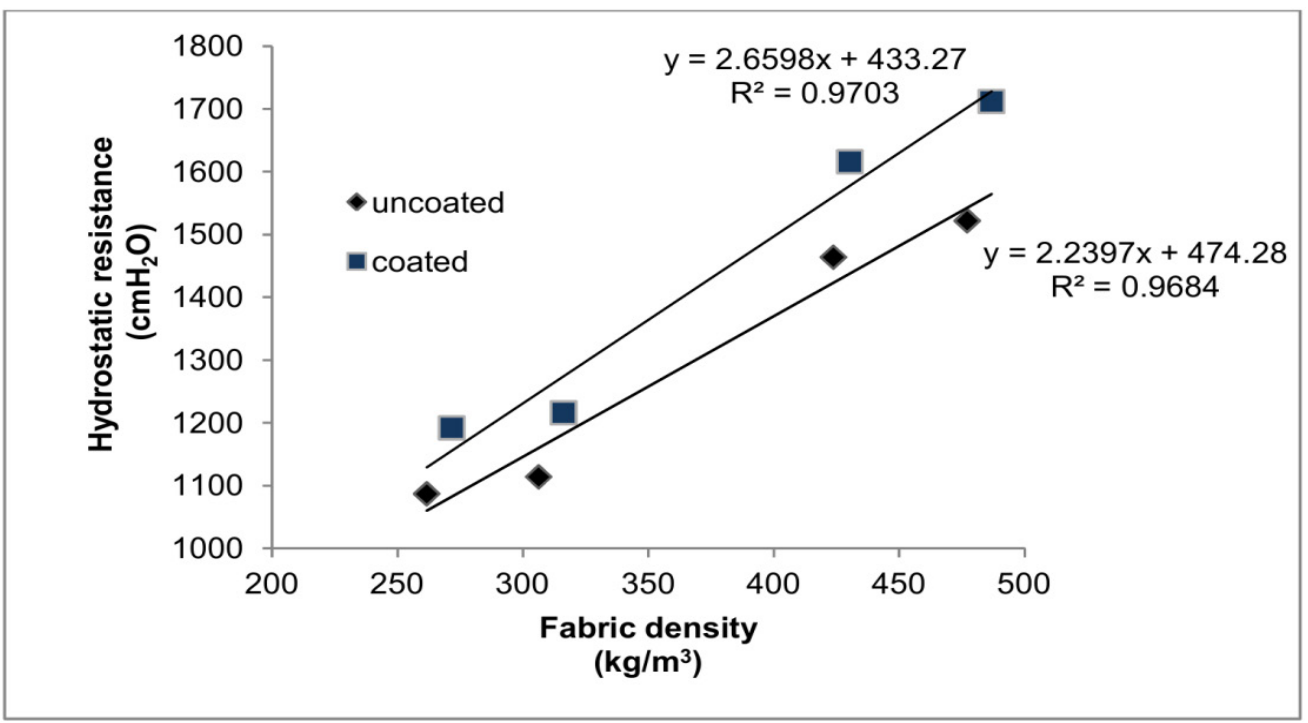

Figure 2. Hydrostatic resistance of uncoated and coated samples 
resistance against water pressure, although their thickness values are higher than others. So, hydrostatic resistance is attributed to fabric density as well as compactness of fabric structure. However, the comparisons between uncoated and coated samples using ANOVA in Table 4 reveals that there are significant increases in hydrostatic resistance after coating for all samples. It is because F-ratios are clearly higher than F-critical values, whereas $P$-values for all samples are less than 0.05 . After coating, increases in hydrostatic resistance for WMK-1 and WMK-2 are 152 and $190 \mathrm{cmH}_{2} \mathrm{O}$, respectively, which are about $10.38 \%$ and $12.48 \%$ increases from uncoated samples. About $9.66 \%$ increase for WMF-3 and $9.16 \%$ increase for WMF4 are found from hydrostatic resistance test results presented in Table 3. These are also significant increases after coating. So, it can be said that there are significant enhancement in hydrostatic resistance for all laminated samples after coating.

\section{Analysis of tensile strength}

To evaluate the mechanical property of the sample fabrics, tensile strength test was performed. From the results of tensile strength test (Table 3), ANOVA (Table 5) and Figure 3 , it is obvious that there are significant increases in tensile strength of all samples after coating. Table 5 shows that the F-ratios are higher than F-critical values and P-values are less than 0.05 in all fabrics when there are comparisons between uncoated and coated samples. The highest increase in tensile strength after coating amongst all samples is found for WMK-2. Here, about $19.67 \%$ increase is obtained after coating because of its denser and more compact structure than others. About $16.34 \%, 15.73 \%$ and $14.78 \%$ increases are found in case of WMK-1, WMF-3 and WMF-4, respectively. It is also clear from Figure 3 that there is a positive relationship between fabric

Table 5. ANOVA for tensile strength of uncoated and coated sample fabrics

\begin{tabular}{|c|c|c|c|c|c|c|c|}
\hline $\begin{array}{l}\text { Compared pairs } \\
\text { (coated and } \\
\text { uncoated) }\end{array}$ & Source of variation & sS & df & MS & F-ratio & P-value & F -critical \\
\hline \multirow{3}{*}{ WMK-1 } & Between groups & $11,424.4$ & 1 & $11,424.4$ & 179.206275 & $9.27894 \mathrm{E}-07$ & 5.3176551 \\
\hline & Within groups & 510 & 8 & 63.75 & & & \\
\hline & Total & $11,934.4$ & 9 & & & & \\
\hline \multirow{3}{*}{ WMK-2 } & Between groups & $21,902.4$ & 1 & $21,902.4$ & 271.573466 & $1.85467 \mathrm{E}-07$ & 5.3176551 \\
\hline & Within groups & 645.2 & 8 & 80.65 & & & \\
\hline & Total & $22,547.6$ & 9 & & & & \\
\hline \multirow{3}{*}{ WMF-3 } & Between groups & $8,065.6$ & 1 & $8,065.6$ & 83.322314 & $1.67004 \mathrm{E}-05$ & 5.3176551 \\
\hline & Within groups & 774.4 & 8 & 96.8 & & & \\
\hline & Total & 8,840 & 9 & & & & \\
\hline \multirow{3}{*}{ WMF-4 } & Between groups & $8,065.6$ & 1 & $8,065.6$ & 65.5473385 & 4.00664E-05 & 5.3176551 \\
\hline & Within groups & 984.4 & 8 & 123.05 & & & \\
\hline & Total & 9,050 & 9 & & & & \\
\hline
\end{tabular}

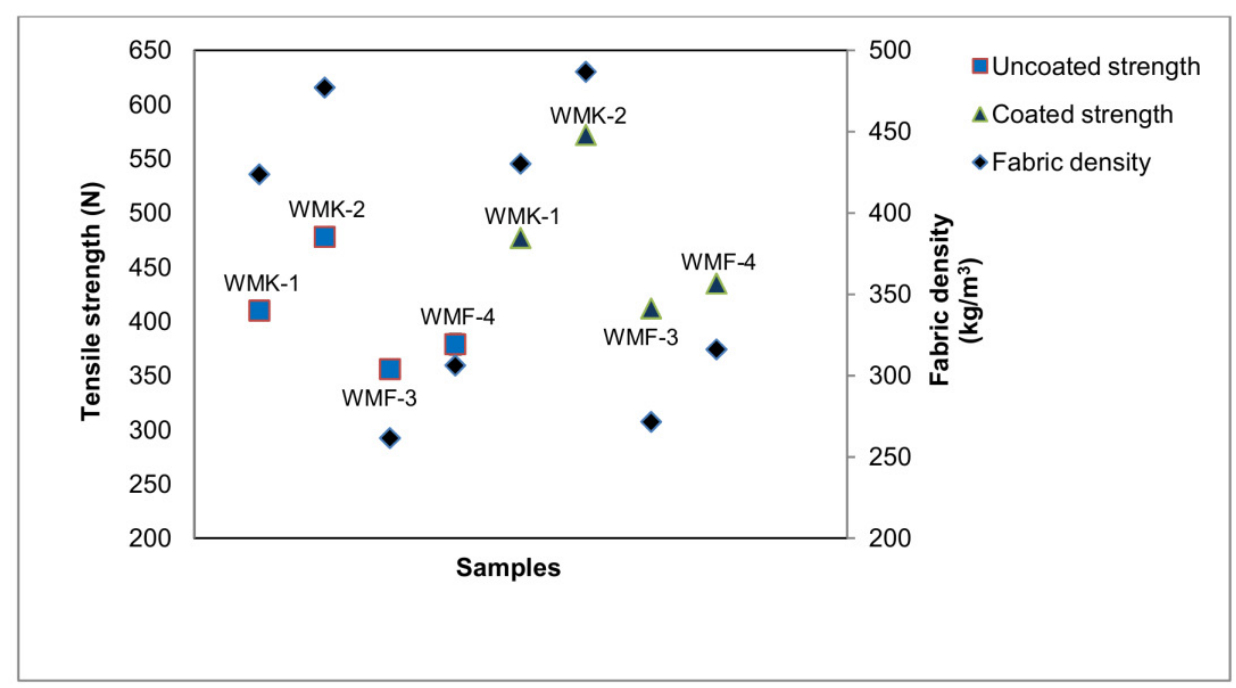

Figure 3. Tensile strength of uncoated and coated samples 
density and tensile strength. Tensile strength increases with the increase in fabric density, and this trend is observed for both uncoated and coated samples. WMK-2 and WMK-1 show higher strength properties than WMF-3 and WMF-4 because of their higher fabric densities in both cases.

\section{Comparison of stiffness}

Stiffness test result represents the rigidity of a fabric. It is a special property of a fabric to keep it standing without support. It is determined by bending rigidity, which is an important comfort parameter. A fabric needs stiffness, but very stiff fabric can be uncomfortable and unfit for use. When uncoated and coated samples are compared using ANOVA (Table 6), F-ratios are higher than F-critical values in case of all samples as well as P-values are less than 0.05. But, from the stiffness test results (Figure 4; Table 3), it can be said that increases in stiffness percentages after coating are not as high as the increases in hydrostatic resistance and tensile strength. Here, maximum increase is obtained for WMK-2 sample after coating, 7.73\%. For WMK-1, WMF-3 and WMF4 samples, $5.95 \%, 5.26 \%$ and $5.09 \%$ increases are found, respectively. These results reveal that there are not much higher increases in stiffness property after coating because of using polysiloxane hydrophobic softening agent in the coating solution.

Table 6. ANOVA for bending rigidity of uncoated and coated sample fabrics

\begin{tabular}{|c|c|c|c|c|c|c|c|}
\hline $\begin{array}{c}\text { Compared pairs } \\
\text { (coated and uncoated) }\end{array}$ & Source of variation & SS & df & MS & F-ratio & P-value & F -critical \\
\hline \multirow{3}{*}{ WMK-1 } & Between groups & 0.49729 & 1 & 0.49729 & 12.689206 & 0.0073771 & 5.3176551 \\
\hline & Within groups & 0.31352 & 8 & 0.03919 & & & \\
\hline & Total & 0.81081 & 9 & & & & \\
\hline \multirow[t]{2}{*}{ WMK-2 } & Within groups & 0.16204 & 8 & 0.020255 & & & \\
\hline & Total & 2.97104 & 9 & & & & \\
\hline \multirow{3}{*}{ WMF-3 } & Between groups & 5.16961 & 1 & 5.16961 & 175.06299 & 1.015E-06 & 5.3176551 \\
\hline & Within groups & 0.23624 & 8 & 0.02953 & & & \\
\hline & Total & 5.40585 & 9 & & & & \\
\hline \multirow{3}{*}{ WMF-4 } & Between groups & 5.12656 & 1 & 5.12656 & 292.11168 & 1.396E-07 & 5.3176551 \\
\hline & Within groups & 0.1404 & 8 & 0.01755 & & & \\
\hline & Total & 5.26696 & 9 & & & & \\
\hline
\end{tabular}

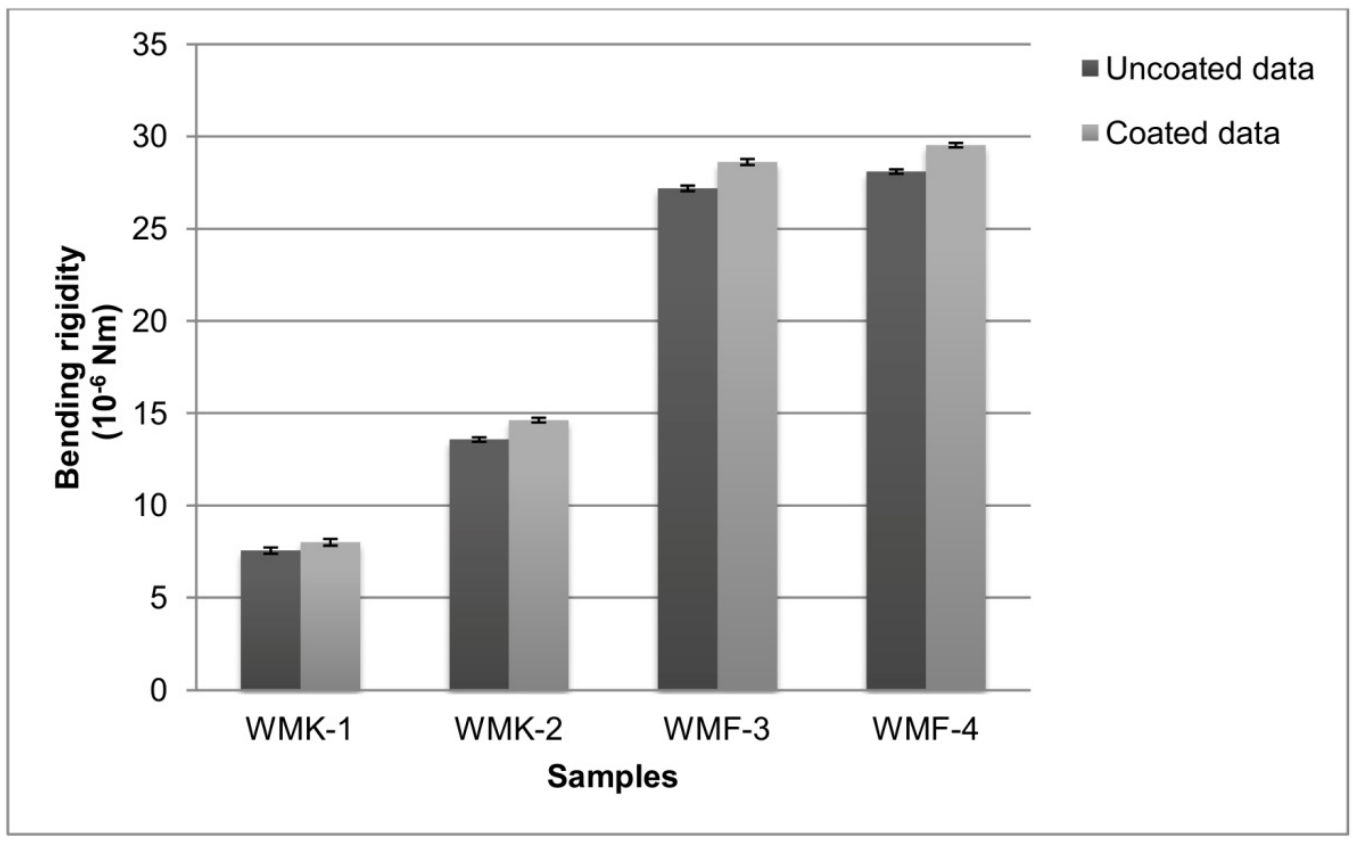

Figure 4. Comparison of bending rigidity for uncoated and coated samples 


\section{Analysis of water vapour permeability}

By measuring evaporative resistance $\left(R_{e t}\right)$ and RWVP\%, water vapour permeability of a fabric is obtained. Higher $R_{\text {et }}$ value and lower RWVP\% determine the lower water vapour transmission of the measuring sample. $R_{\text {et }}$ represents difference in the water vapour pressure between the two sides of the specimen divided by the resultant evaporative heat flux per unit area in the direction of the gradient, which is expressed as $\mathrm{m}^{2} \mathrm{~Pa} / \mathrm{W}$. The effect of fabric weight on water vapour permeability for both uncoated and coated samples is shown in Figure 5. It is evident that $R_{\text {et }}$ values of all samples increase with the increases in fabric weights in both cases. The fabric becomes uncomfortable with increasing the fabric weight and evaporative resistance. Amongst the four samples, WMF-3 and WMF-4 samples have the lower water vapour permeability because of their higher $R_{\text {et }}$ values. The reason is their higher fabric weights and inner knitted fleece structures cause more air entrapment, preventing the diffusion rate of water vapour. As a result, it can be difficult to release sweat from the body in the form of water vapour. On the other hand, WMK-1 and WMK-2 samples show better water vapour permeability because of their lower fabric weight properties. Again, WMK-1 sample has less densely outer woven structure and less stitch density of inner knitted structure along with lower thickness and lower fabric weight, which make it best water vapour permeable amongst all the samples. These results are in accordance with the previous study [14]. The more water vapour transmission of this fabric results in higher fabric breathability.

From Table 7, it can be said that there are no significant changes in $R_{\text {et }}$ values for uncoated and coated samples because F-ratios are lower than F-critical values and $\mathrm{P}$-values are more than 0.05 . The reason is that the hydrophobic water-repellent

Table 7. ANOVA for evaporative resistance $\left(R_{e t}\right)$ of uncoated and coated sample fabrics

\begin{tabular}{|c|c|c|c|c|c|c|c|}
\hline $\begin{array}{l}\text { Compared pairs } \\
\text { (coated and uncoated) }\end{array}$ & Source of variation & SS & df & MS & F-ratio & P-value & F-critical \\
\hline \multirow{3}{*}{ WMK-1 } & Between groups & 0.225 & 1 & 0.225 & 2.8846154 & 0.1278591 & 5.3176551 \\
\hline & Within groups & 0.624 & 8 & 0.078 & & & \\
\hline & Total & 0.849 & 9 & & & & \\
\hline \multirow{3}{*}{ WMK-2 } & Between groups & 0.441 & 1 & 0.441 & 4.2 & 0.0745788 & 5.3176551 \\
\hline & Within groups & 0.84 & 8 & 0.105 & & & \\
\hline & Total & 1.281 & 9 & & & & \\
\hline \multirow{3}{*}{ WMF-3 } & Between groups & 0.196 & 1 & 0.196 & 2.9037037 & 0.1267779 & 5.3176551 \\
\hline & Within groups & 0.54 & 8 & 0.0675 & & & \\
\hline & Total & 0.736 & 9 & & & & \\
\hline \multirow{3}{*}{ WMF-4 } & Between groups & 0.144 & 1 & 0.144 & 1.8823529 & 0.2073048 & 5.3176551 \\
\hline & Within groups & 0.612 & 8 & 0.0765 & & & \\
\hline & Total & 0.756 & 9 & & & & \\
\hline
\end{tabular}

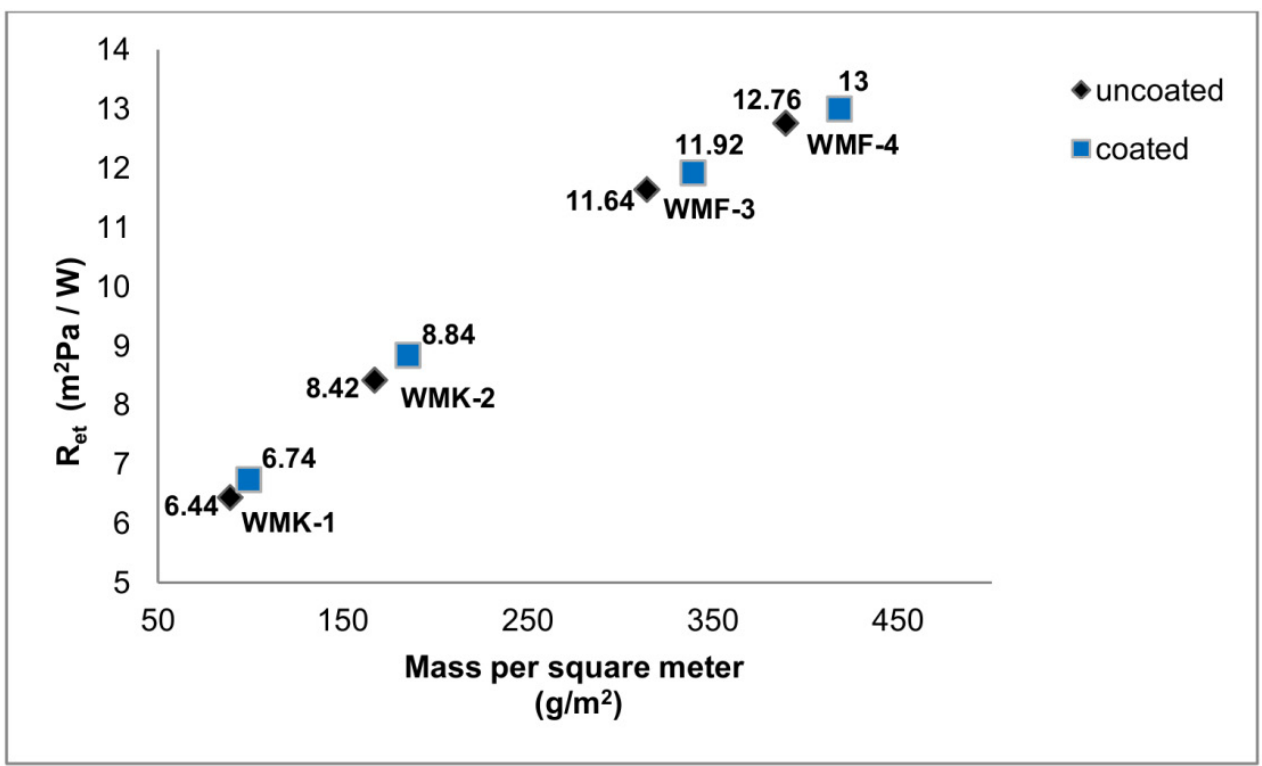

Figure 5. Evaporative resistance $\left(R_{e t}\right)$ of uncoated and coated samples 
coating applied to a fabric has no great effect on the diffusion process [16]. As a result, no significant change in water vapour permeability is obtained after coating for any sample.

\section{Comparison of air permeability}

In order to determine the changes in air permeability after coating for all samples, ANOVA (Table 8) and Figure 6 can be used. In the table, F-ratios of all samples are lower than F-critical values and $\mathrm{P}$-values are more than 0.05 , which indicates that there are no significant changes in air permeability after coating for all fabric samples. Figure 6 also reveals the same appearance that there are actually no big differences in air permeability between uncoated and coated samples. So, it can be said that the effects of applied water-repellent coating solution on air permeability of different laminated fabrics are not significant.

\section{Conclusion}

In this research work, hydrostatic resistance and tensile strength of uncoated and coated layered waterproof breathable laminated fabrics were experimentally investigated and compared whilst considering their other properties, such as stiffness, water vapour permeability and air permeability. The water-repellent coating solution applied along with softening agent on the fabric samples significantly enhanced the hydrostatic resistance and tensile strength. From $9.16 \%$ to $12.48 \%$ increases in hydrostatic resistance were found after coating in different samples and increases in tensile strength were obtained from $14.78 \%$ to $19.67 \%$, which were quite significant increases after coating. Moreover, all the fabrics showed highest water-repellent property with '100' rating during spray test. Stiffness was also increased after coating,

Table 8. ANOVA for air permeability of uncoated and coated sample fabrics

\begin{tabular}{|c|c|c|c|c|c|c|c|}
\hline $\begin{array}{c}\text { Compared pairs } \\
\text { (coated and uncoated) }\end{array}$ & Source of variation & SS & df & MS & F-ratio & P-value & F-critical \\
\hline \multirow{3}{*}{ WMK-1 } & Between groups & 0.004805 & 1 & 0.004805 & 2.453617 & 0.1346655 & 4.4138734 \\
\hline & Within groups & 0.03525 & 18 & 0.0019583 & & & \\
\hline & Total & 0.040055 & 19 & & & & \\
\hline \multirow{3}{*}{ WMK-2 } & Between groups & 0.007605 & 1 & 0.007605 & 3.113259 & 0.0946201 & 4.4138734 \\
\hline & Within groups & 0.04397 & 18 & 0.0024428 & & & \\
\hline & Total & 0.051575 & 19 & & & & \\
\hline \multirow{3}{*}{ WMF-3 } & Between groups & 0.019845 & 1 & 0.019845 & 4.3663366 & 0.0511226 & 4.4138734 \\
\hline & Within groups & 0.08181 & 18 & 0.004545 & & & \\
\hline & Total & 0.101655 & 19 & & & & \\
\hline \multirow{3}{*}{ WMF-4 } & Between groups & 0.01922 & 1 & 0.01922 & 3.7934211 & 0.0672246 & 4.4138734 \\
\hline & Within groups & 0.0912 & 18 & 0.0050667 & & & \\
\hline & Total & 0.11042 & 19 & & & & \\
\hline
\end{tabular}

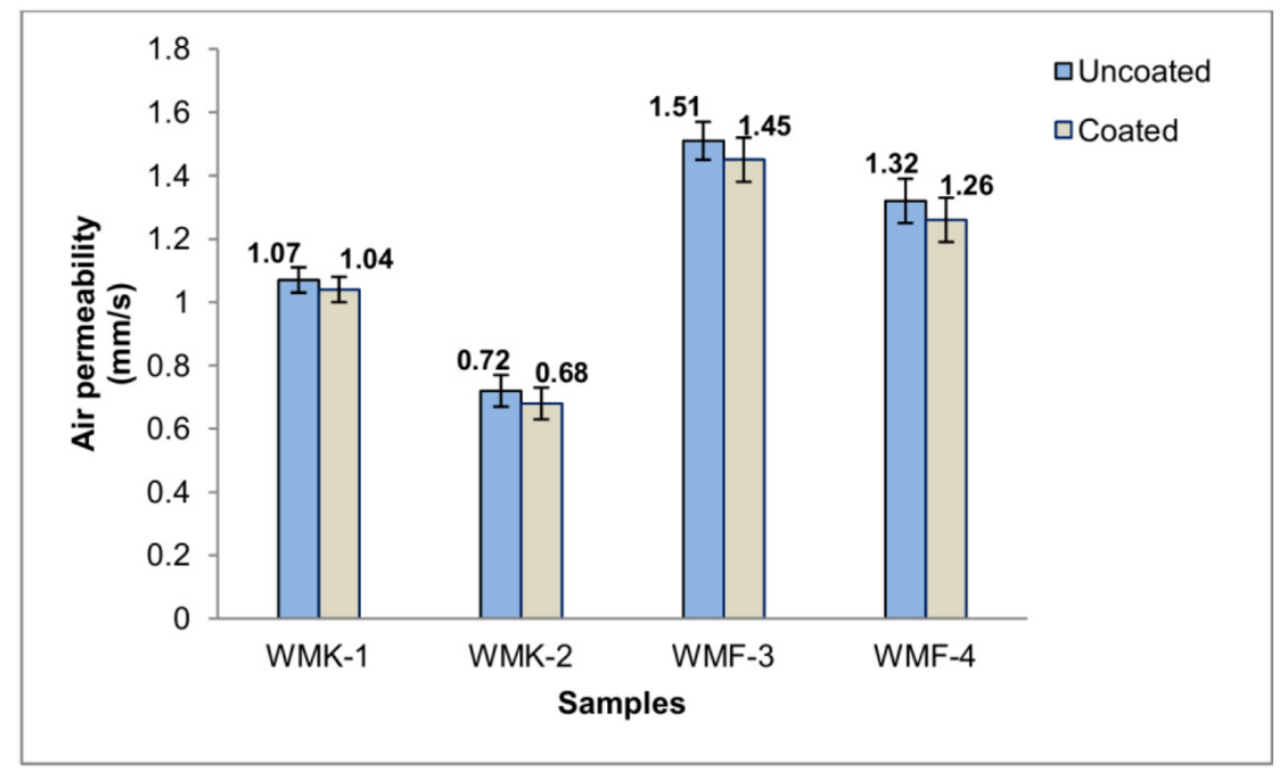

Figure 6. Air permeability of uncoated and coated samples 
but it was not as much higher increase as the increases of hydrostatic resistance and tensile strength because of using hydrophobic softening agent. However, no significant increases or no big differences were obtained in water vapour permeability after coating in different samples, which indicated no significant changes in breathability for coating. Increases in air permeability were also insignificant for all samples after coating.

Finally, it can be concluded from the experiment that application of water-repellent coating with softening agent on different laminated waterproof layered fabrics showed significant enhancement of hydrostatic resistance and tensile strength with proper water repellency, but there were no big effects of applied coating on their breathability and air permeability properties.

\section{ACKNOWLEDGEMENTS}

This study was supported by the development programme of SGS 2017 at Technical University of Liberec in the Czech Republic.

\section{References}

[1] Ahmad, S., Ahmad, F., Afzal, A., Rasheed, A., Mohsin, M. $\&$ Ahmad, N. (2015). Effect of weave structure on thermophysiological properties of cotton fabrics. AUTEX Research Journal, Vol. 19, No 1, March 2019, 15(1), 30-34.

[2] Ahn, H. W., Park, C. H. \& Chung, S.E. (2010). Waterproof and breathable properties of nanoweb applied clothing. Textile Research Journal, 81, 1438-1447.

[3] Boguslawska-Baczek, M. \& Hes, L. (2013). Effective water vapour permeability of wet wool fabric and blended fabrics. Fibers and Textiles in Eastern Europe, 21, 67-71.

[4] Chen, Q., Miao, X., Mao, H., Ma, P. \& Jiang, G. (2016). The comfort properties of two differential-shrinkage polyester warp knitted fabrics. AUTEX Research Journal, Vol. 19, No 1, March 2019, 16(2), 90-99.

[5] Chinta, Dr. S. K. \& Satish, D. (2014). Studies in waterproof breathable textiles. International Journal of recent development in engineering and technology, 3, 16-20.

[6] Das, B., Das, A., Kothari, V., Fanguiero, R. \& Araujo, M. $D$. (2009). Moisture flow through blended fabrics - effect of hydrophilicity. Journal of Engineered Fibers and Fabrics, 4, 20-28.
[7] Fridrichova, L (2013). A new method of measuring the bending rigidity of fabrics and its application to the determination of the their anisotropy. Textile Research Journal, 83, 883-892.

[8] Gretton, J. C., Brook, D. B., Dyson, H. M. \& Harlock, S. C. (1998). Moisture Vapor transport through waterproof breathable fabric and clothing systems under a temperature gradient. Textile Research Journal, 68, 936-941.

[9] Kale, B. M., Wiener, J., Militky, J., Rwawiire, S., Mishra, R., Jacob, K. I. \& Wang, Y. (2016). Coating of cellulose-TiO2 nanoparticles on cotton fabric for durable photocatalytic self-cleaning and stiffness. Carbohydrate Polymers, 150, 107-113.

[10] Kang, Y. K., Park, C. H., Kim, J. \& Kang, T. J. (2007). Application of electrospun polyurethane web to breathable waterproof fabrics. Fibers and Polymers, 8, 564-570.

[11] Maqsood, M., Nawab, Y., Shaker, K., Umair, M., Ashraf, M., Baitab, D. M., Hamdani, S.T.A. \& Shahid, S. (2016). Modelling the effect of weave structure and fabric thread density on mechanical and comfort properties of woven fabrics. AUTEX Research Journal, Vol. 19, No 1, March 2019, 16(3), 160-164.

[12] Mukhopadhyay, A. \& Midha, V. (2008). A review on designing the waterproof breathable fabrics. Part-l: Fundamental principles and designing aspects of breathable fabrics. Journal of Industrial Textiles, 37, 225-262.

[13] Ozcan, G. (2007). Performance evaluation of water repellent finishes on woven fabric properties. Textile Research Journal, 77, 265-270.

[14] Ozen, I. (2012). Multi-layered breathable fabric structures with enhanced water resistance. Journal of Engineered Fibers and Fabrics, 7, 63-69.

[15] Save, N. S., Jassal, M. \& Agrawal, A. K. (2002). Polyacrylamide based breathable coating for cotton fabric. Journal of Industrial Textiles, 32, 119-138.

[16] Wang, J. H. \& Yasuda, H. (1991). Dynamic water vapor and heat transport through layered fabrics. Part-l: Effect of surface modification. Textile Research Journal, 61, 10-20.

[17] Yadav, A. K., Kasturiya, N. \& Mathur, G. N. (2002). Breathability in polymeric coatings. Man-Made Textiles in India, 45, 56-60.

[18] Yoon, H. N., Sawyer, L. C. \& Buckley, A. (1984). Improved comfort polyester. Part-ll: Mechanical and surface properties. Textile Research Journal, 54, 357-365.

[19] Zhu, G., Kremenakova, D., Wang, Y. \& Militky, J. (2015). Air permeability of polyester nonwoven fabrics. AUTEX Research Journal, Vol. 19, No 1, March 2019, 15(1), 8-12. 